Result In the analysed period, a total of 2218 vaccines were administered, with a progressive increase from 302 (2012) to 659 (2016) per year (mean \pm SD: 444 \pm 150 ). Focusing on $2016,49.3 \%$ of the vaccinated subjects were students or residents, $42.0 \%$ HCWs, $7.0 \%$ administrative staff and 1.7\% volunteers. Among $\mathrm{HCW}$, the mean age of the vaccinated subjects was higher than the mean age of all hospital staff (49.5 vs 45.9 , p-value $<0.05)$. Men were more vaccinated than women $(12.3 \%$ vs $7.6 \%$, p-value $<0.05)$. The highest vaccination coverage was among medical doctors (21.3\%), followed by administrative staff (8.7\%), nurses and midwives (6.5\%), and other healthcare workers (3.4\%). Among students, the highest vaccination coverage was in medical students (33.2\%), followed by nursing and midwifery students (8.2\%), and other healthcare students $(6.3 \%)$.

Conclusion In Italy, the increasing flu vaccination rates was likely due to the growing public concern regarding infectious diseases, particularly meningococcal meningitis. Older HCWs were the most vaccinated, probably because age and its related disorders raise awareness on the importance of vaccination. In this sense, they use vaccination in order to protect themselves. The higher vaccination coverage among doctors and medical students suggests an important influence of education.

\section{HEALTHCARE WORKERS AND BLOODBORNE PATHOGEN EXPOSURE INCIDENTS}

A Franko, M Dodic Fikfak, N Sestan. Clinical Institute of Occupational Medicine, University Medical Centre, Ljubljana, Slovenia

\subsection{6/oemed-2018-ICOHabstracts.993}

Introduction Healthcare workers are at risk of infection caused by bloodborne pathogens, particularly hepatitis B (HBV), hepatitis $\mathrm{C}(\mathrm{HCV})$ and human immunodeficiency virus (HIV) due to sharps injuries and skin and mucous membrane contacts with blood or other potentially infectious materials. Our aim was to evaluate the reporting, management and consequences of bloodborne pathogen exposure incidents in healthcare workers.

Methods The study included all healthcare workers of the largest University Medical Centre in Slovenia (UMCL) who reported bloodborne incidents and were treated from 1 January 2008 to 31 December 2016 according to the guidelines. The data were collected from medical records.

Result The average number of employed healthcare workers was 5492. The mean incidence rate of annually reported and treated incidents was 2.22 per 100 health workers. Average annual injuries incidence rates were the highest at the Dental Clinic (9.83 per 100), Department of Surgery (2.86 per 100) and Department of Internal Medicine (2.25 per 100). Incidents occurred most frequently in nurse's aides $(5.79$ per $100)$, followed by doctors (2.28 per 100) and nurses (1.69 per 100). The most common were sharps injuries (1.93 per $100)$, followed by contact of eye (0.11 per 100) and skin (0.04 per 100) with blood. The most frequent cause was contact when disposing of used needles (39.83\%). Incidents most commonly happened on Fridays. Approximately $81 \%$ of exposed workers were vaccinated against HBV before the incident. Among the reported cases, one became HBsAg positive after the incident, while none of them was anti-HCV or antiHIV reactive during the follow-up.
Discussion More work-related interventions are needed to prevent bloodborne incidents among healthcare workers. Therefore, we are developing an educational campaign to raise awareness of the importance of prevention, reporting and treating bloodborne exposure incidents and vaccination against HBV.

\section{THE JOB DEMAND-CONTROL-SUPPORT AND EFFORT- REWARD-IMBALANCE MODELS APPLIED ON SWEDISH HOSPITAL WORKERS IN THE OPERATION THEATRE}

${ }^{1} \mathrm{R}$ Wålinder*, ${ }^{1} \mathrm{R}$ Runeson-Broberg, ${ }^{2} \mathrm{E}$ Arakelian, ${ }^{1} \mathrm{~T}$ Nordquist, ${ }^{1} \mathrm{~A}$ Runeson, ${ }^{1} \mathrm{~A}$ RaskAnderson. 'Occupational and Environmental Medicine, Department of Medical Sciences, Uppsala University, Sweden; ${ }^{2}$ Department of Surgical Sciences, Uppsala University, Sweden

\subsection{6/oemed-2018-ICOHabstracts.994}

Introduction There is a global shortage of healthcare workers. The aim of the present study is to describe the psycho-social work climate for hospital workers in the operating theatre via the job demand-control-support (JDCS) and effort-reward imbalance (ERI) models and relate to well-being, work-ability, zest for work and thoughts about leaving the job.

Methods Hospital workers in the operating theatre of 7 Swedish hospitals $(n=1405$, response rate $68 \%)$ received a questionnaire including the JDCS model, ERI model, personal factors, well-being, work-ability, zest for work and thoughts about leaving their job. Ordinal scale regression was used for analyses.

Results Descriptively a majority reported moderate to high zest for work (76\%). A minority (30\%) had sometimes thought of leaving their jobs for at least one month during the last year. Social support was positively related to wellbeing, zest for work and inversely related to thoughts about leaving the job. Workers reporting low well-being, poor zest for work and more thoughts about leaving the job scored at average in the active field of the demand-control diagram and operating nurses were the only category with mean scores in the strain field, in comparison to all personnel. Also relations to the ERI model will be presented (in progress by June 2017).

Discussion The social support dimension of the JDCS model was the main occupational factor related to well-being and positive thoughts about keeping the job. Lack of external comparison groups, small variability and poor internal consistency of the control index make conclusions about the demand-control dimensions less reliable.

\section{THE DESIGN AND DEVELOPMENT OF A 'HUB AND SPOKE MODEL' FOR HEALTHCARE WORKERS IN THE PUBLIC HEALTH SERVICE IN IRELAND}

L Sisson*, S Carolan. Workplace Health and Wellbeing Unit, HSE, Human Resources, Dublin, Ireland

\subsection{6/oemed-2018-ICOHabstracts.995}

Introduction The Health Service Executive (Ireland) Mission clearly states that people in Ireland are supported by health and social care services to achieve their full potential. It identified access, safe, compassionate and quality care as priorities. The HSE Corporate Plan 2015-2017 set our values of Care, Compassion, Trust and Learning. 
Methods With proposed changes in the Irish Health Services and the development of commissioning services/service provision in the Community Healthcare Organisation/Hospital Group Model, the most effective model of care is a central governance unit i.e. WHWU with areas covered geographically by defined Area/collaborative service delivery units, this is referred to as a 'hub and spoke' model. The structure of each hub includes occupational health physician services, occupational health nursing services, employee assistance programmes, rehabilitation services, health promotion, health and safety, and the provision of governance and support.

The targets for the area/collaborative service delivery units, 'hub and spoke' model will be exactly as described by the Healthy Staff, Better Care for Patients. www.dh.gov.uk 2011.

Result This model of care will be implemented over Q.2 2017 to Q2 2018

In order to meet these service needs there must be integration with local health and Safety, stress management services, rehabilitation services, health and wellbeing and counselling services.

- Prevention - of ill health caused or exacerbated by work

- Timely intervention- easy and early treatment for the main cause of sickness absence.

- Rehabilitation - to help staff stay at work or return to work after illness

- Health Assessments for work- to help manage attendance, retirement and related matters

- Promotion of health and well being - using work as a means to improve health and well being and using the workplace to promote health

- Teaching and training - encouraging staff and managers to support staff health and well-being.

Discussion The role of the Workplace Health and Wellbeing is to progress the 'Hub and Spoke' model and to evaluate the effectiveness.

\section{CLEANING AND DISINFECTION IN HOME HEALTHCARE: INTEGRATING QUALITATIVE AND QUANTITATIVE METHODS TO ASSESS CAREGIVERS' EXPOSURE TO CLEANING AND DISINFECTION PRODUCTS}

\begin{abstract}
${ }^{1}$ Pia Markkanen*, ${ }^{1}$ Margaret Quinn, ${ }^{2}$ Nancy Goodyear* ${ }^{1}$ Catherine Galligan, ${ }^{1}$ David Kriebel, ${ }^{1}$ Susan Sama, ${ }^{1}$ Rebecca Gore, ${ }^{1} J o h n$ Lindberg, ${ }^{2}$ Christian Beato-Melendez, ${ }^{1}$ Nicole Karlsson, ${ }^{2}$ Hagir Mohamed, ${ }^{1}$ Noor Sheikh, ${ }^{3}$ Alexis Parker-Vega* . ${ }^{1}$ Department of Public Health, University of Massachusetts Lowell, Lowell, USA; ${ }^{2}$ Department of Biomedical and Nutritional Sciences, University of Massachusetts Lowell, Lowell, USA; ${ }^{3}$ Office of Environment, Health and Safety, University of California San Francisco, San Francisco, USA
\end{abstract}

\subsection{6/oemed-2018-ICOHabstracts.996}

Introduction In the United States, home care (HC) aide is one of the fastest growing jobs. Aides perform both personal care and cleaning and disinfection (C and D) tasks in the clients' homes. There is clear scientific evidence of asthma and other respiratory effects with $\mathrm{C}$ and $\mathrm{D}$ work. This presentation demonstrates how mixed research methods assessed the nature of $\mathrm{C}$ and D work and health-related exposures in HC.

Methods The Safe Home Care Project conducted 9 focus groups comprising $80 \mathrm{HC}$ aides and 5 in-depth interviews with HC employers' and workers' representatives. All focus groups and interviews were audio-recorded and transcribed verbatim. Computer-assisted thematic analysis of all transcripts was conducted. The results informed the development of (i) the microbiology field study in 46 seniors' homes to measure micro-organisms and soil on common household surfaces and how effectively 'green' and bleach-containing products cleaned these surfaces, and (ii) the laboratory study to measure airborne $\mathrm{C}$ and D product exposures among HC aides $(n=20)$ who performed $\mathrm{C}$ and $\mathrm{D}$ tasks in a simulated bathroom with 4 different products.

Result HC aides sanitise bathrooms and kitchens frequently. Bleach-containing products are commonly applied and HC clients mostly decide which $\mathrm{C}$ and D products are used. The microbiology study showed that both 'green' and bleach-containing products removed micro-organisms on tested surfaces. The laboratory study showed that the bleach-containing cleaning product generated high airborne chlorine exposures: over $60 \%$ of the aides exceeded $1 \mathrm{ppm}$ for chlorine - a permissible exposure limit of the US Occupational Safety and Health Administration.

Discussion Mixed methods research techniques provide complementary data for assessing and characterising $\mathrm{C}$ and $\mathrm{D}$ exposures in HC. Use of bleach-containing products can generate high airborne chlorine exposures. Chlorine is a respiratory irritant. It seems prudent to limit the unnecessary use of bleach in HC and carefully discern - on a client-by-client basis - whether bleach is needed for infection prevention.

\section{OCCUPATIONAL HEALTH AND SAFETY ISSUES OF ETHICAL DILEMMAS FACED BY NURSES IN CLINICAL PRACTICE SETTINGS: A QUALITATIVE STUDY}

${ }^{1} \mathrm{C}$ Caux*, ${ }^{1} \mathrm{~F}$ Dupuis, ${ }^{2} \mathrm{~K}$ Lechasseur, ${ }^{3} \mathrm{~J}$ Lecomte. 'Université de Montréal, Canada; ${ }^{2}$ Université Laval, Québec, Canada; ${ }^{3}$ CIUSS Centre-Sud-de-l'̂le-de-Montréal, Canada

\subsection{6/oemed-2018-ICOHabstracts.997}

Introduction During their practice, nurses regularly encounter ethical dilemmas. The sources of these dilemmas, according to the literature, seem mainly related to clinical practice settings, such as emergency, intensive, palliative, oncology, etc. However, as part of a graduate clinical ethics course for nurses, we also noticed that the sources of nurse ethical dilemmas seem to be very much related to occupational safety and health $(\mathrm{OSH})$ considerations as opposed to clinical situations. This research aimed to highlight these sources of ethical dilemmas that can be attributed to contexts and aspects other than those found in the literature, particularly those related to OSH.

Methods Ethical dilemmas were assessed qualitatively by analysing 250 written descriptions presented by students in the graduate clinical ethics course for nurses. Each description was analysed using the continuous comparison technique in order to produce an emergent model, which reconstructed the nurses' representations of ethical dilemmas pertaining to $\mathrm{OSH}$. Results The results provide a much broader picture of the ethical dilemmas faced by nurses. The model shows that the majority of ethical dilemmas described has underlying dynamics related to OSH. They described ethical dilemmas arising from an explicit risk to their physical or psychological health such as exposure to biological agents, bullying or threats from the patient's family. Moreover, many of the ethical dilemmas are expressed by the nurses primarily in terms of consequences for herself and not for the patient.

Conclusion This model emphasises that OSH issues have a significant impact on ethical dilemmas experienced by nurses. Consequently, these issues should be part of the discussions regarding ethical climate in nursing management and education. 